\title{
Practical Work of Digital System Course Based on Virtual Laboratory
}

\author{
https://doi.org/10.3991/ijoe.v17i08.23359
}

\author{
Rudi Mulya, Krismadinata $\left({ }^{\varpi}\right)$, Nizwardi Jalinus, Hansi Effendi \\ Universitas Negeri Padang, Indonesia \\ krismalft.unp.ac.id
}

\begin{abstract}
In this paper, a virtual laboratory is used for digital systems practice courses which are carried out online. The research step begins with designing a virtual laboratory portal with Moodle E-Learning software to provide practice management services. The trial was carried out by running an online collaborative practice by applying the Breadboard simulator and the TeamViewer application. The research subjects were 20 students of the Informatics Engineering study program. The data collection instrument used a student perception questionnaire on the instructional aspect and a student perception questionnaire on the appearance of the learning model and ease of operation. Descriptive analysis was carried out using perception level criteria. The results showed that the virtual laboratorybased Digital System practice learning model had a positive perception of the instructor aspect, the learning model display aspect and ease of operation as well as increasing student motivation in carrying out practical activities.
\end{abstract}

Keywords—virtual laboratory, digital system course, JavaBreadboard, TeamViewer, collaborative online

\section{Introduction}

Practical work is learning that aims to test, apply theory, and scientific proof of a course or part of a particular subject. Practical work is usually carried out in traditional laboratories (hands-on) which have characteristics with several weaknesses, such as (1) unable to meet the needs of distance learning; (2) making students feel uncomfortable during practice; (3) requires more time for instructors; (4) unable to provide special needs for students; and (5) expensive equipment procurement and operations [1]. This is also reinforced by the results of preliminary research [2] which revealed that the practice equipment used had not accommodated all the material and the limited time so that it had not achieved the expected learning objectives.

Along with the development of science and technology, especially information and communication technology, the concept of electronic laboratory (e-lab) has developed. In its implementation, e-lab can be realized in the form of a remote laboratory (r-lab) and virtual laboratory (v-lab). As an alternative, virtual laboratories are very interesting to implement because virtual laboratories are a good concept to understand 
theoretical topics better [3]. The main component of the v-lab is a simulator that provides simulation functions and phenomena that occur in practical activities.

Previous research has proven that simulators: (1) can improve students' understanding of the material [4][5]; (2) as effective as using real laboratories [6][7][8][9][10]; (3) can be more efficient than real laboratories [11][12]; and (4) provides high convenience and flexibility [13]; (5) allows to practice in real systems[14], low cost, and has a better pedagogical aspect than other types of laboratories [15]; (6) increasing the number of lab sessions and the number of student teams/groups per week [16]; (7) wide accessibility, because it can be accessed anywhere and anytime; (8) safer during experiments with hazardous substances [17][18][19], and (9) promote a resilient, inclusive and sustainable approach to supplement knowledge and training resources and common limitations to laboratory skill training [20]. Based on these advantages, virtual laboratories can be applied to Digital Systems courses when viewed from the characteristics of these courses.

In Digital Systems courses, practice usually uses breadboards to implement digital circuits. Since 2010 Breadboard exists in a simulator version that runs on a desktop or standalone computers containing digital devices such as chips or ICs and logic gates, sequential circuits such as counters, registers, combinational circuits that are displayed in virtual/simulation form [21].

Simulation models provide several advantages, such as (1) providing experiences that are difficult to experience in the real world; (2) increase safety when studying interactions with physical objects or phenomena; (3) easy to set the activity time; (4) turning rare events into ordinary events; (5) enabling the control of a more complex learning environment; (6) enabling cost savings [19]; and (7) facilitate students to learn independently and can practice repeatedly outside the practice class [22].

Practicing using virtual laboratories can be more flexible if this technique can be applied with e-learning, even some have developed m-learning as was done by [23]. The online teaching model has been developed by [24] but has not been facilitated by using online collaborative methods. The reason for using collaborative learning is because it has advantages in four main categories namely: social, psychological, academic, and assessment such as helping to develop a social support system for students; build an understanding of diversity among students and lecturers; build a positive atmosphere, practice collaboration, and develop a learning community [25].

This study uses the model [24] and the supporting instruments adopted from the study [26]. The purpose of this study was to determine the application of a virtual laboratory-based practice model for the Digital Systems course. This model is supported by several software such as e-learning Moodle, Breadboard simulator, and TeamViewer.

\section{$1.1 \quad$ E-learning moodle}

Moodle e-learning is used to provide administrative services from practice with the address of the virtual laboratory portal https://diexpressmulya.com/. An example of a portal display like Figure 1. 


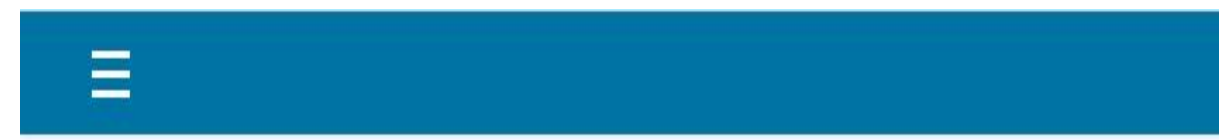

\section{Open Edu}

Education is the learning of knowledge, skills, and habits of a group of people that are passed down from one generati often takes place under the guidance of others, but it is also possible t

\section{Open Edu}

\section{Available courses}

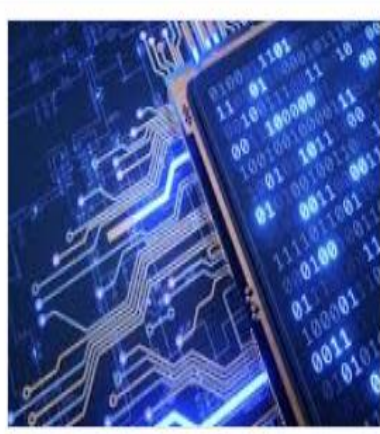

Digital Syotem Practice

ReadMore 》

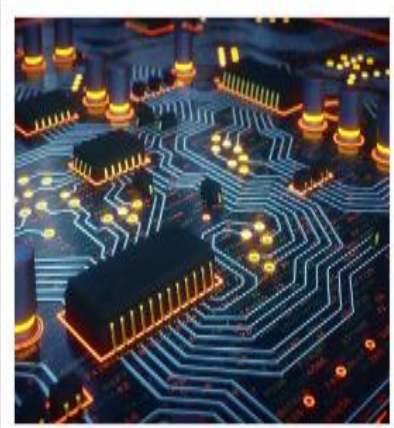

Digital Electronico Practice

\section{ReadMore 》}

Fig. 1. Laboratory portal display

\subsection{Breadboard simulator}

The Breadboard Simulator was developed by a team from York University UK's Department of Computer Science. This simulator is a desktop application program created with a Java program and can be run on a local computer with a Windows operating system. The breadboard simulator can run properly if hardware and soft- 
ware are available with the following specifications: (1) The available hardware can be a desktop or laptop computer with standard specifications for operating desktop applications such as Microsoft Office; (2) Windows family operating systems such as Windows XP, Windows 7, or Windows 10; (3) Java Runtime Environment (JRE) program must be installed. The breadboard simulator interface can be seen in Figure 2.

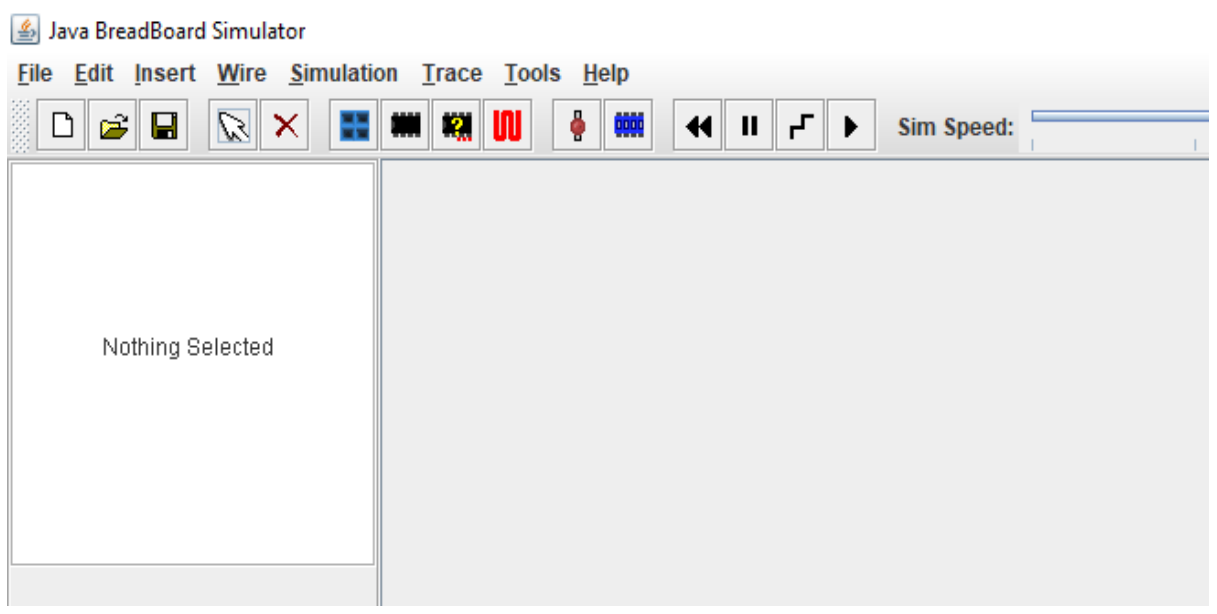

Fig. 2. Breadboard simulator interface

\subsection{TeamViewer}

TeamViewer is software that is used to support online practice activities that can provide a collaborative approach where there are remote control functions and online meetings. TeamViewer can be used to (1) display the desktop for meetings, presentations, or collaborations; (2) meeting functions, for example for training sessions; (3) meeting apps for Android and iOS to participate in meetings on the go; (4) provide ad-hoc remote support to colleagues, friends or customers; (5) establish connections between different computers and operating systems; (6) TeamViewer runs under Windows, Mac OS or Linux. The application interface is shown in Figure 3. 


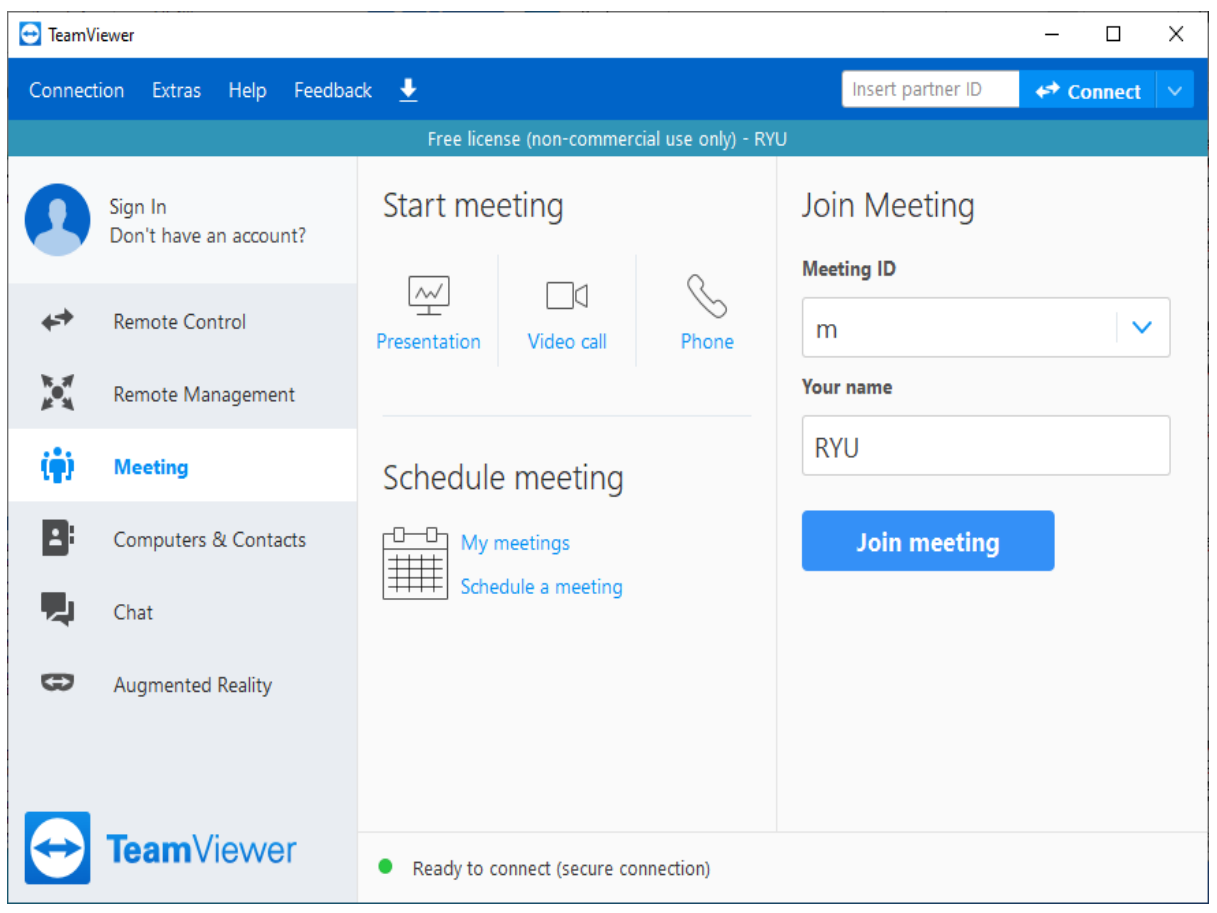

Fig. 3. TeamViewer application interface

\subsection{Online Practice Model}

The online practice model as shown in Figure 4 on the top left, describes an online learning model with a collaborative approach. The existence of interaction between students and students in synchronous, asynchronous, and general learning such as online classes shows that there is an interaction between lecturers and students. Meanwhile, on the top right, it shows an online independent learning model that shows direct interaction between students and the material. The interaction of the lecturer with the material on the lower right shows that the lecturer's activities are focused on preparing the syllabus, learning materials, and planning learning activities. Through this activity, lecturers can monitor, organize, and update materials and learning activities that will be carried out.

On the top left, the application of practice using an online collaboration approach can be done. That is, the medium of communication between students and the material must be available; implementation using the Breadboard simulator can be implemented. The interaction or relationship between students and lecturers and the interaction or relationship between students and students must have a system. To make these two interactions, we can use the remote control and online meeting features of the TeamViewer application. The model developed by [24] can be used as the basis for the online practice model which can be seen in Figure 4. Anderson explained that the top left describes an online learning model with a collaborative approach that shows 
synchronous or asynchronous interactions between students and students, and general learning such as online classes, which show interactions between lecturers and students. While the picture on the right shows an online independent learning model, this shows direct interaction between students and the material. The interaction of the lecturer with the material on the right side of the picture shows that the lecturer's activities are focused on preparing the syllabus, learning materials, and planning learning activities. Through these interactions, lecturers can monitor, compile, and update materials and learning activities that will be carried out.

The interaction of materials and materials shown in the picture above is a new model of interaction in the world of education that has emerged along with the rapid development of information and communication technology. Through the online learning model, learning materials can be programmed so that they automatically interact with other sources of learning materials for enrichment and updating of their contents. Meanwhile, interactions between lecturers and other lecturers are carried out so that online learning can be guaranteed for lecturers with different materials.

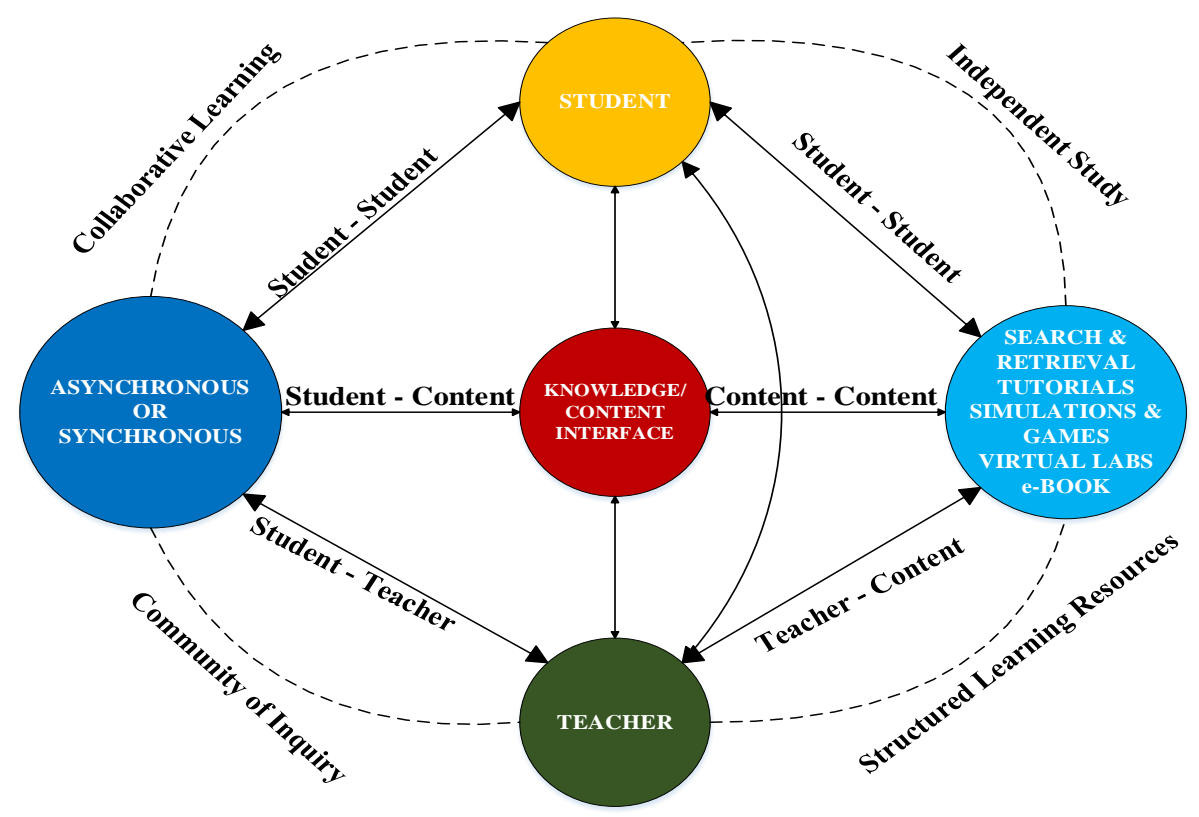

Fig. 4. Online practice model

\section{Methods}

This experimental research aims to determine the application of a virtual laboratory-based Digital System practice. Experiments were carried out by designing a virtual laboratory portal using Moodle e-learning software to provide administrative services from practice with the address https://diexpressmulya.com/ then testing was carried 
out by conducting collaborative practice online by implementing Breadboard and TeamViewer simulators.

The display of e-learning moodle for practice implementation management can be seen in Figure 5.
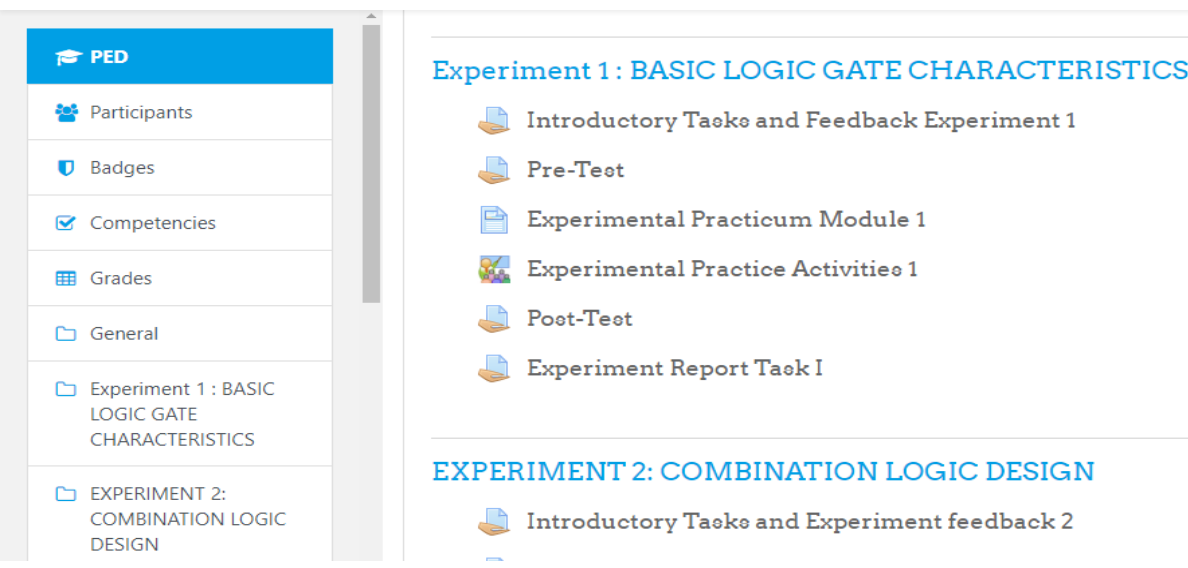

Introductory Taeke and Experiment feedback 2

Fig. 5. Moodle e-learning display for practice implementation management

The following activities are carried out by students during practice learning, which is described in the following Table 1.

Table 1. Student activities in practical learning in virtual laboratories

\begin{tabular}{|l|c|c|}
\hline No & Activity & Time \\
\hline 1 & Work on and submit preliminary assignments & Before practice \\
\hline 2 & Doing the pretest & When practice \\
\hline 3 & Carry out online practice & When practice \\
\hline 4 & Doing posttest & When practice \\
\hline 5 & Work on and send report assignments & After practice \\
\hline
\end{tabular}

Then when the practice is carried out students access the breadboard simulator, because this practice activity emphasizes cooperation or collaboration between group members in conducting experiments. The collaboration is done online synchronously, so students must take advantage of all existing synchronous communication facilities such as chat and video conferencing in the TeamViewer application. An example of the display during the practice can be seen in Figure 6 . 


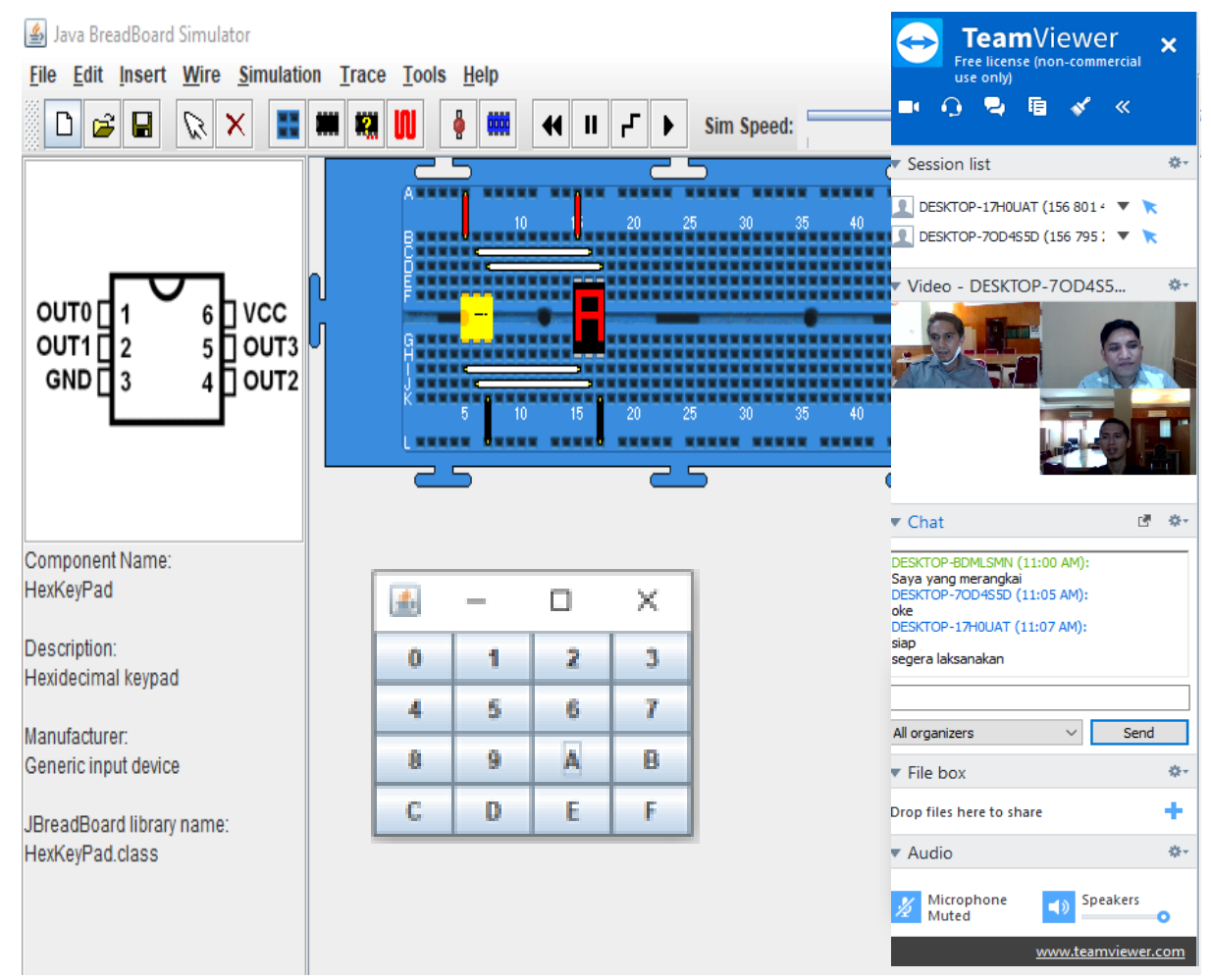

Fig. 6. Display during online practice

The research sample was 20 students of the Informatics Engineering Study Program who were participants in the Digital Systems Practice course. The instrument used for data collection is a questionnaire, namely (1) students' perceptions of the instructional aspects, (2) students' perceptions of the learning model and ease of operation.

Data on student perceptions of the instructional aspect contains the following components: (1) clarity of basic competencies and objectives; (2) clarity of instructional learning; (3) ease of understanding practical material; (4) the breadth and depth of the material (5) the accuracy of the presentation sequence; (6) interactivity; (7) flexibility; (8) evaluation accuracy [21].

Data on student perceptions about aspects of the learning model and ease of operation were obtained through a questionnaire containing the following components: (1) clarity of instructions for use; (2) legibility; (3) the quality of the display of images and animations; (4) color composition; (5) the quality of communication facilities; and (6) ease of operation [21].

Determination of perceptual tendencies is done by using the percentage technique using equation (1) as follows:

$$
P=\frac{\left(n_{1} \times 1\right)+\left(n_{2} \times 2\right)+\left(n_{3} \times 3\right)+\left(n_{4} \times 4\right)+\left(n_{5} \times 5\right)}{N \times 5} \times 100 \%
$$


The explanation of the formula in equation (1) is $\mathrm{P}$ indicates the percentage of perception, $n_{1}, n_{2}, n_{3}, n_{4}, n_{5}$ each is the number of choices for the score $1,2,3,4,5$ for choices STS (strongly disagree), TS (disagree), R (undecided), S (agree), SS (strongly agree); and $\mathrm{N}$ indicates the number of questionnaire items.

The success of the implementation of the virtual laboratory-based digital system practice learning model can be known based on the data collected and analyzed descriptively and using the criteria for the level of student perception as in Table 2.

Table 2. Criteria for the level of students' perceptions about the learning model of virtual laboratory-based digital system practices

\begin{tabular}{|l|c|}
\hline \multicolumn{1}{|c|}{ Range } & Level \\
\hline $80 \%-100 \%$ & Very Good \\
\hline $66 \%-79 \%$ & Good \\
\hline $56 \%-65 \%$ & Poor \\
\hline $0 \%-55 \%$ & Very Poor \\
\hline
\end{tabular}

\section{$3 \quad$ Results and Discussion}

Testing of student perception data about the instructional aspects of the Digital System Practice based on a digital laboratory can be seen in Table 3.

Table 3. Student perceptions about instructional aspects

\begin{tabular}{|l|c|c|c|}
\hline \multirow{2}{*}{ Component } & \multicolumn{2}{c|}{ Student } & \multirow{2}{*}{ Maximum Score } \\
\cline { 2 - 3 } & Score & $\%$ & \\
\hline Clarity of basic competencies \& objectives & 496 & 70.86 & 700 \\
\hline Clarity of learning instructions & 227 & 75.67 & 300 \\
\hline Ease of understanding material \& running practices & 280 & 70 & 400 \\
\hline The breadth and depth of the material & 227 & 75.67 & 300 \\
\hline The accuracy of the order of presentation & 304 & 76 & 400 \\
\hline Interactivity & 147 & 73.50 & 200 \\
\hline Flexibility & 146 & 73 & 200 \\
\hline Evaluation accuracy & 385 & 77 & 500 \\
\hline Total & 2212 & & 3000 \\
\hline$\%$ average & & 73.73 & \\
\hline
\end{tabular}

The results of the analysis of student perceptions about the practical learning aspects of virtual laboratory-based digital systems are shown in Figure 7. 


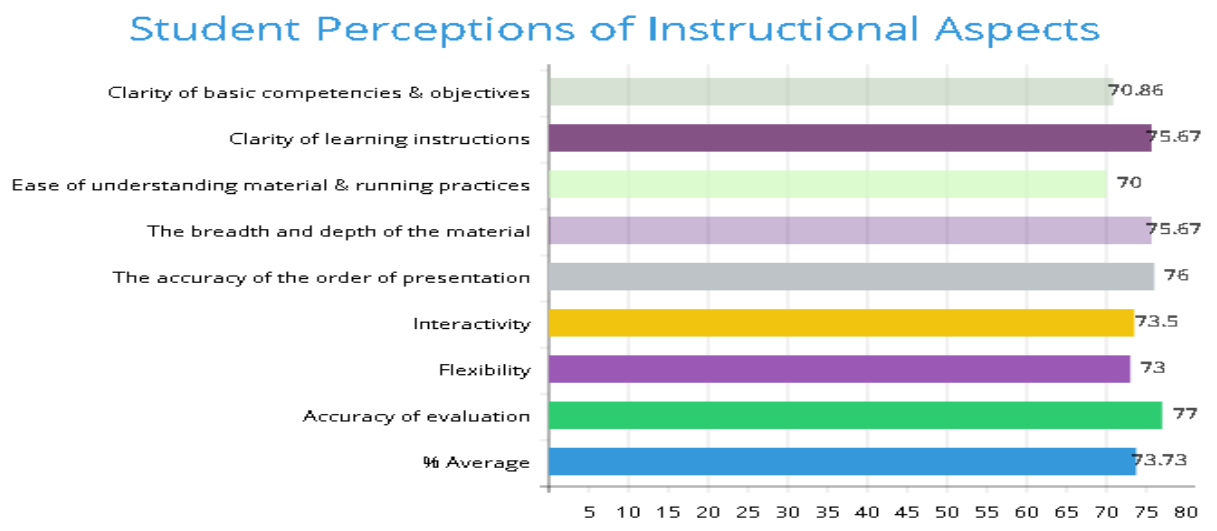

Fig. 7. Student perceptions of instructional aspects

In the instructional aspect, the results showed that the average student had a good perception of $70.86 \%$ on the aspect of clarity of basic competencies and goals. Based on the items of the instruments used, these results show that the application of the learning model includes basic competencies and learning objectives that must be achieved by students, formulated in a simple, operational, and communicative language. In this case, students also feel that the formulation of learning objectives listed in the model can increase motivation in achievement and show clear stages towards competency achievement, and have been known before the practice is carried out.

In the aspect of learning clarity, students also have a good perception at an average level of $75.67 \%$. This fact shows that the learning instructions contained in the model set are online learning guidelines, simulator use guidelines, and Digital Systems Practice guidelines that are easy to learn.

A good perception is also given by students for ease of understanding the material or carrying out practice with an average percentage value of $70 \%$. These results indicate that students feel that they have gained new knowledge after the implementation of the practice. It also shows that students view the learning model as a communicative language and contain material in practical activities so that it is easy to implement and easy to learn. However, from this study, it was also found that students still had difficulty doing online training activities with a perception level of $70 \%$. The difficulties that arise are mostly related to lecturers' constraints for the internet provided, including the limited available bandwidth so that access to data is slowly related to the application of the required online practice.

The perception of area and depth of material obtained is on average $75.67 \%$. Based on the average value obtained shows that students do not feel difficulties when practicing because the material found in the model that is applied is not too easy, but also not too difficult and is still within the scope of students' abilities and aspects of the breadth and depth of the material provide positive perception.

In terms of the presentation of practice material, students gave a good perception of the presentation aspects with an average value of $76 \%$. Students feel the presentation of material has been done systematically so that it is interesting, easy to understand, and attention 
and shows the relationship between close practice topics, material that is provided in stages is provided from simple to more complicated, or from abstract to concrete.

Furthermore, the interactivity aspect gained an average perception level of $73.5 \%$. Based on these values it can be interpreted that the applied learning model has provided tools that can encourage collaboration, enhance collaborative activities in groups, and high interactions occur between students and the tools provided.

From this research, it was found that students see online practice learning compared to practice using a real laboratory as more fun, a high level of flexibility in terms of time, and a place of practice that can be done anywhere and anytime. This is shown by a good level with a percentage of $73 \%$ of the aspects of flexibility.

Student perceptions about the accuracy of the evaluation reached a good level with a percentage value of $77 \%$. Based on these results shows that the application of the model has met the requirements: (1) material questions by the concept of the material provided in practical activities, (2) the level of difficulty of the questions given gradually from the easy level to the more difficult level, (3) provide pretest and posttest questions that fit the learning objectives in each practice, (4) the questions given can encourage students to think critically, systematically, logically, and analytically, and (5) the questions presented can strengthen mastery of the material.

Based on the results of the analysis of the perception component on aspects of learning that have been done, it can be concluded that students provide positive perceptions with an average percentage of $73.73 \%$. The data tests students' perceptions about the appearance of a virtual laboratory-based learning interface in Table 4.

Table 4. Students' perceptions about the interface of the virtual laboratory-based practice learning model

\begin{tabular}{|l|c|c|c|}
\hline \multirow{2}{*}{\multicolumn{1}{|c|}{ Component }} & \multicolumn{2}{c|}{ Student } & \multirow{2}{*}{ Maximum Score } \\
\cline { 2 - 3 } & Score & $\%$ & 600 \\
\hline Clarity of use instructions & 456 & 76.50 & 300 \\
\hline Legibility & 243 & 81 & 300 \\
\hline Image display quality & 238 & 79.33 & 300 \\
\hline Color composition & 245 & 81.67 & 400 \\
\hline Quality of communication facilities & 279 & 69.75 & 400 \\
\hline Ease of operation & 312 & 78 & 2300 \\
\hline Total & 1776 & & \\
\hline$\%$ Average & & 77.22 & \\
\hline
\end{tabular}

An analysis of student perceptions about the interface of the virtual laboratorybased practice learning model is shown in Figure 8. 


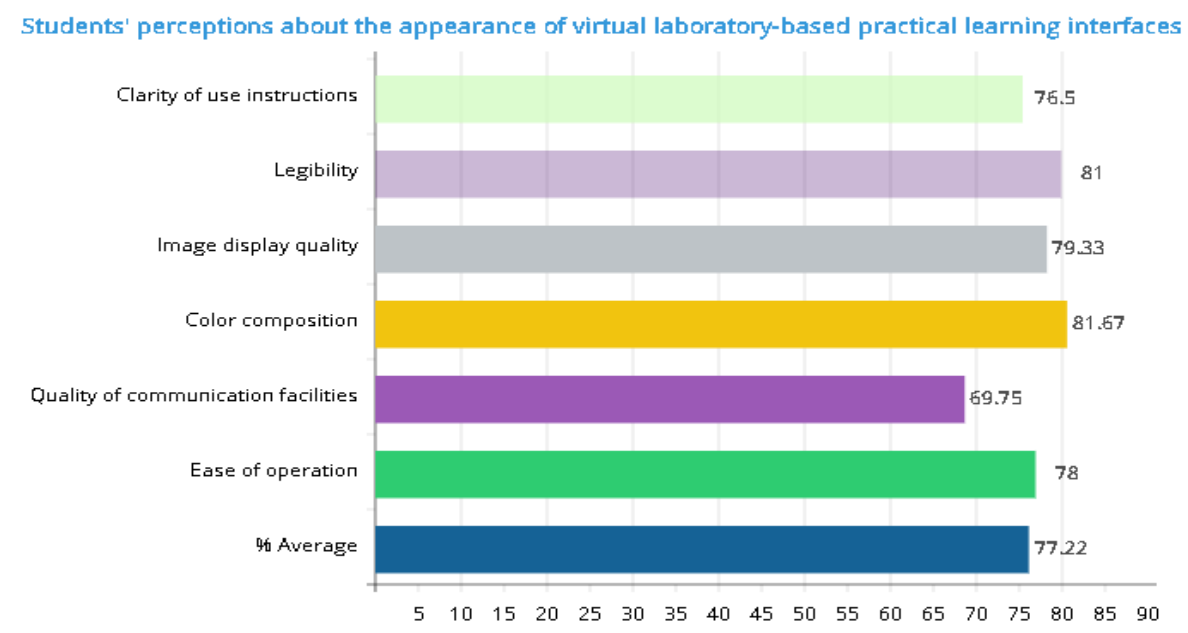

Fig. 8. Students' perceptions about the appearance of virtual laboratory-based practical learning interfaces

Figure 8 showed that students gave a good perception of the aspects of clarity of instruction for use with an average perception level of $76.5 \%$. This level of perception illustrates that from the student's perspective, the applied model is equipped with instructions for use that are easy to learn and easy to apply.

Table 3 also shows that product readability is felt very well by students as indicated by the value of the average perception level of $81 \%$. These results illustrate that the display of letters on (1) virtual laboratory portal as a way to manage online practice administration (2) Breadboard simulator program as a means to replace real tools and materials, and (3) TeamViewer program as a work tool online collaboration, easy to read so that is very helpful for student understanding.

The image quality of the learning model applied is also considered good by students. This is reflected in the value of the average perception level of $79.33 \%$. This shows that the images and illustrations listed on the product, especially those provided by virtual laboratory portals, simulator programs, and online collaboration support programs, are of good quality that attracts interest and motivates students to learn.

The color composition aspect gained very good perception by instructors and students with an average level of $81.67 \%$. These results indicate that in the subject's perception, the color composition of the model and supporting devices have been arranged to produce a good composition and pleasing to the eye.

In the aspect of communication quality, qualitative data obtained by several students give a bad perception. This is because sometimes students experience unexpected technical obstacles such as limited internet connection speeds so that the completeness of online practices cannot be carried out normally. However, in general, with an average perception level of $69.75 \%$, students have given a good perception about the aspects of communication facilities provided by the learning model. This shows that communication facilities such as chat rooms, video conferencing, voice- 
over IP, and file transfers can be used easily and smoothly in supporting online practice activities.

While the aspect of ease of operation gained a $78 \%$ perception rate which indicates that the product being developed, in the subject's perception, is easy to operate. The ease of operation of this product is marked by the results of the subject assessment which shows the menus provided by the learning tools are easily recognized, read, understood, and run.

Based on the results of the analysis of perceptions about the appearance of a virtual laboratory-based learning interface as has been done above, it can be concluded that from the perspective of students, the applied learning model has given a good performance with an average perception level of $77.22 \%$.

Practice Digital Systems that usually use real laboratories have several weaknesses. So that the research is carried out using a virtual laboratory. The results obtained are good perceptions from students in terms of the perception components on the instructional aspects and the appearance of the virtual laboratory model. These results are in line with [7] which states that virtual laboratories are as effective as using real laboratories, can be done anywhere and anytime [2], and facilitate students to learn independently and can practice repeatedly outside class [18].

This study proves that virtual laboratories have many advantages in line with research results [22] which states that the use of virtual environments and student performance has a positive relationship. The supporting application contained in the virtual laboratory, namely the JavaBreadboard simulator, can be used to simulate and prove concepts related to digital systems courses. This is in line with the results of research [3][14] which states that simulators can improve students' understanding of learning material. In a virtual laboratory, collaboration can also be done online through a supporting application, namely TeamViewer, which provides a collaborative approach in which there is an online meeting device.

\section{Conclusion}

Research conducted has shown that the work practice of Digital System course based on virtual laboratory can be applied and this model obtains positive perceptions from related subjects. This is related to aspects of the appearance of a virtual laboratory-based learning interface, ease of operation, and increased student motivation in conducting practical activities.

The model shows clear stages towards competency achievement, starting from before the practice, during the practice, and after the practice is carried out. A practical Digital System based on a virtual laboratory is more fun when compared to a real laboratory and high flexibility in terms of time and place can be done anywhere and anytime. In virtual laboratories, collaboration can also be done online using supporting applications such as TeamViewer.

The online collaboration program provided by the application Team Viewer does not provide a login history documentation facility so that it causes lecturers to not be able to monitor student practical activities asynchronously, so it is advisable to devel- 
op this model at times will need to pay attention to the availability of the login history facility its users.

\section{$5 \quad$ References}

[1] Ma J. and Nickerson, J. V. (2006). "Hands-on, simulated, and remote laboratories: A comparative literature review," ACM Comput. Surv., vol. 38, no. 3, p. 1. https://doi.org/10.114 5/1132960.1132961

[2] Utami, P., Cikarge, G. P., Ismail, M. E. and Hashim, S. (2018).“Teaching Aids in Digital Electronics Practice through Integrating 21st Century Learning Skills using a conceptual approach," J. Phys. Conf. Ser., vol. 1140, no. 1. https://doi.org/10.1088/1742-6596/ $1140 / 1 / 012022$

[3] Kumar V. and Kumari, S. (2016). "A Study Virtual Laboratory : Objective , Comparison and Benefits," Int. J. Innov. Adv. Comput. Sci., vol. 5, no. 6, pp. 71-73.

[4] Colace, F., De Santo, M. and Pietrosanto, A. (2014). "Work in progress - Virtual lab for electronic engineering curricula," Proc. - Front. Educ. Conf. FIE, vol. 1, pp. 2-5, 2004. https://doi.org/10.1109/fie.2004.1408524

[5] Suwannakhun S. and Tanitteerapan, T. (2017). "Design and development of distance laboratory package for teaching basic electronics via cloud computing," Int. J. Online Eng., vol. 13, no. 8, pp. 60-78. https://doi.org/10.3991/ijoe.v13i08.6985

[6] Tzafestas, C. S., Palaiologou, N. and Alifragis, M. (2006). "Virtual and remote robotic laboratory: Comparative experimental evaluation," IEEE Trans. Educ., https://doi.org/10. 1109/te.2006.879255

[7] Prieto-Blázquez, J., García-Torà, I., Herrera-Joancomartí, J. and Guerrero-Roldán, A. E. (2008). "Virtual laboratory ontology for engineering education," Proc. - Front. Educ. Conf. FIE, https://doi.org/10.1109/fie.2008.4720470

[8] Lang, D., Mengelkamp, C., Jäger, R. S., Geoffroy, R. S., Billaud, M. and Zimmer, T. (2007). "Pedagogical evaluation of remote laboratories in eMerge project," Int. J. Phytoremediation, vol. 32, no. 1, pp. 57-72, https://doi.org/10.1080/03043790601055626

[9] Goodwin, G. C., Medioli, A. M., Sher, W., Vlacic, L. B. and Welsh, J. S. (2011). "Emulation-based virtual laboratories: A low-cost alternative to physical experiments in control engineering education," IEEE Trans. Educ., https://doi.org/10.1109/te.2010.2043 434

[10] Candelas, F. A., Torres, F., Gil, P., Puente, S. and Pomares, J. (2006). "Including the virtual laboratory concept in an on-line collaborative environment," in IFAC Proceedings Volumes (IFAC-PapersOnline), 2006, https://doi.org/10.3182/20060621-3-es-2905.00098

[11] Saleh, K. F., Mohamed, A. M. and Madkour, H. (2009). "Developing Virtual Laboratories Environments for Engineering Education," Int. J. Arts Sci..

[12] Mateev, V., Todorova, S. and Smrikarov, A. (2007). "Test system in Digital Logic Design virtual laboratory - Tasks delivery," in ACM International Conference Proceeding Series, https://doi.org/10.1145/1330598.1330683

[13] Bailey C. and Freeman, M. J. (2009). "Java Breadboard Simulator Digital Circuit Simulation With An Extensible E-Learning Tool," IADIS - Int. Assoc. Dev. Inf. Soc., vol. 1, no. 2, pp. 299-306.

[14] Abreu, P., Barbosa, M. R. and Lopes, A. M. (2015). "Experiments with a virtual lab for industrial robots programming," Int. J. Online Eng., vol. 11, no. 5, pp. 10-16, https://doi .org/10.3991/ijoe.v11i5.4752 
[15] Macias M. E. and Mendez, I. (2007). "eLab - Remote Electronics Lab in Real Time," in Frontiers In Education Conference - Global Engineering: Knowledge Without Borders, Opportunities Without Passports, 2007. FIE '07. 37th Annual, pp. 12-16, https://doi. org/10.1109/fie.2007.4418154

[16] Shokri A. and Faraahi, A. (2010). "Designing of Virtual Laboratories Based on Extended Event Driving Simulation Method," World Acad. Sci. Eng. Technol. Int. J. Econ. Manag. Eng., vol. 4, No. 8, no. 8, pp. 1935-1937.

[17] Malki H. A. and Matarrita, A. (2003). "Web-based control systems laboratories using LabVIEW," J. Eng. Technol..

[18] Palagin O. et al., (2007). "Virtual laboratory for computer-aided design: Typical virtual laboratory structure and principles of its operation," in 2007 4th IEEE Workshop on Intelligent Data Acquisition and Advanced Computing Systems: Technology and Applications, IDAACS, https://doi.org/10.1109/idaacs.2007.4488378

[19] Bernarducci, M. (2016). "Multimedia for Learning: Methods and Development (3Th Edition) - Book Review," Eur. J. Educ. Stud., vol. 1, no. 1, pp. 50-56.

[20] Kumar, D., Radhamani, R., Nizar, N., Achuthan, K., Nair, B. and Diwakar, S. (2018). "Virtual and remote laboratories augment self learning and interactions: Development, deployment and assessments with direct and online feedback," PeerJ, vol. 6, https://doi. org/10.7287/peerj.preprints. 26715

[21] Elawady Y. H. and Tolba, A. (2009). "Educational Objectives Of Different Laboratory Types: A Comparative Study," Int. J. Comput. Sci. Inf. Secur., vol. 6 No. 2, pp. 89-93.

[22] Hassan, R. (2010). "DigiLab: A Virtual Lab for IT Students," WSEAS Trans. Adv. Eng. Educ., vol. 7, no. 5, pp. 151-160.

[23] Wang, N., Chen, X., Song, G., Lan, Q. and Parsaei, H. R. (2017). "Design of a New Mobile-Optimized Remote Laboratory Application Architecture for M-Learning," IEEE Trans. Ind. Electron., vol. 64, no. 3, pp. 2382-2391, https://doi.org/10.1109/tie.2016. 2620102

[24] Anderson, T. (2008). "The Theory and Practice of Online Learning," Language Learning Technology.

[25] Laal M. and Laal, M. (2011). "Collaborative learning: What is it?," Procedia - Soc. Behav. Sci., vol. 31, no. 2011, pp. 491-495, 2012, https://doi.org/10.1016/j.sbspro.2011.12.092

[26] Muchlas, (2013) "Pengembangan Model Pembelajaran Online Untuk Praktik Teknik Digital Program Pascasarjana Universitas Negeri Yogyakarta,".

\section{Authors}

Rudi Mulya is completed his Bachelor of Engineering in the Department of Electrical Engineering, Faculty of Engineering, University of Andalas. Obtained his Computer Master's Degree in Universitas Putra Indonesia (UPI) YPTK Padang Postgraduate Program in Information Technology. Pursue Dr. degree at Universitas Negeri Padang. E-mail: rudimuly4@gmail.com

Krismadinata received the B.Eng. degree from University of Andalas, Padang, Indonesia and the M.Eng. degree from the Bandung Institute of Technology, Indonesia. Doctor of Philosophy (Ph.D.) Electrical and Electronics Engineering from University Malaya. A Lecturer in electrical engineering, Universitas Negeri Padang since 2006. A Research Engineer with the Center of Research for Power Electronics, Drives, Automation and Control, Faculty of Engineering, University of Malaya, 
Kuala Lumpur, Malaysia. Research interests are power electronics control and renewable. E-mail: krisma@ft.unp.ac.id

Nizwardi Jalinus Completed the Mechanical Engineering Education undergraduate program at Universitas Negeri Padang in 1978 and the Doctoral program in Vocational Education in 1998 at the University of Tasmania, Australia. Currently a professor at the Faculty of Engineering, Universitas Negeri Padang. E-mail: nizwardi@ft.unp.ac.id

Hansi Effendi is Completed undergraduate studies (S1) in the Department of Electrical Engineering, Faculty of Engineering, University of Andalas, Padang. Completed undergraduate studies (S2) in the Postgraduate Program in Computer Science at the Universitas Putra Indonesia (UPI) YPTK Padang. Completed undergraduate studies (S3) in the Postgraduate Program in Technology and Vocational Education at Universitas Negeri Yogyakarta (UNY). Teaching staff in the Department of Electrical Engineering, Faculty of Engineering, Universitas Negeri Padang (FT-UNP) since 2002. Now actively researching on: development of ICT based learning models. E-mail: hans_79@ft.unp.ac.id

Article submitted 2021-04-16. Resubmitted 2021-06-02. Final acceptance 2021-06-04. Final version published as submitted by the authors. 